ORIGINAL ARTICLE

\title{
Twelve-month trajectories of depressive and anxiety symptoms and associations with traumatic exposure and ongoing adversities: a latent trajectory analysis of a community cohort exposed to severe conflict in Sri Lanka
}

\author{
AK Tay ${ }^{1}$, R Jayasuriya ${ }^{2}$, D Jayasuriya ${ }^{3}$ and D Silove ${ }^{1}$
}

We conducted a 12-month follow-up of a population sample of adults from districts (Mannar, Killinochi, Mullaitivu and Jaffna) exposed to high levels of mass conflict in Sri Lanka, the aim of the present analysis being to identify trajectories of depression and anxiety symptoms and their associations with exposure to psychological trauma and ongoing living adversities. The cohort of 1275 adults (response 86\%) followed-up in 2015 was a structured subsample drawn from the baseline nationally representative survey conducted in 2014 across 25 districts in Sri Lanka. Interviews were conducted using electronic tablets by field workers applying contextually adapted indices of trauma exposure, ongoing adversities and symptoms of depression and anxiety. Latent transition analysis revealed a three-class longitudinal model from which four composite trajectories were derived, comprising a persistent symptom trajectory $(n=555,43.5 \%)$, an incident or new onset trajectory $(n=170,13.3 \%)$, a recovery trajectory $(n=299,23.5 \%)$ and a persistently low-symptom trajectory $(n=251,19.7 \%)$. Factors associated with both the persistent symptom and incident trajectories were female gender, past trauma exposure and lack of access to health services. Loss of a job was uniquely associated with the persisting trajectory at follow-up. The recovery trajectory comprised a higher proportion of men, older persons and those without risk factors. Our findings assist in translating epidemiologic data into public policy and practice by indicating the importance of stable employment and the provision of healthcare as key factors that may act to reduce anxiety and depressive symptoms in the post-conflict phase. The findings also confirm that women are at high risk of mental distress. Brief screening for trauma exposure in populations with high levels of exposure to mass conflict may assist in defining those at risk of ongoing symptoms of anxiety and depression.

Translational Psychiatry (2017) 7, e1200; doi:10.1038/tp.2017.166; published online 8 August 2017

\section{INTRODUCTION}

Population-focused mental health surveys applying screening measures have identified a high prevalence of depression and anxiety symptoms among communities exposed to mass conflict and displacement compared to societies that have remained unaffected by these upheavals., ${ }^{1,2}$ In general, these inquiries confirm that survivor populations manifest high levels of anxiety and depressive symptoms, at least in the short- and medium-term following conflict. ${ }^{3}$ An important task, however, is to design and analyse epidemiological studies in a manner that ensures their capacity for translation into effective public policy, a key aim being to define subpopulations that follow distinctive symptom trajectories over time. In particular, it is important to identify and characterize two subpopulations: those with persisting symptoms and those at risk of new onset distress. In addition, from a public health and translational perspective, it is vital to identify potentially modifiable factors that shape symptom trajectories, knowledge that will direct social recovery programs toward strategies that are most likely to mitigate or prevent mental distress in the community as a whole.
By far the majority of extant epidemiological studies in the field are incapable of providing definitive evidence relating to the aforementioned issues because of their cross-sectional design, ${ }^{2}$ the few existing longitudinal studies in the field being limited by their non-representative designs and modest sample sizes. ${ }^{4-6}$ An additional issue is whether it is necessary to measure symptoms of both anxiety and depression, given that these symptom constellations overlap and/or show a pattern of transition from one pattern to the other over time.?

An approach to achieve these translational outcomes has been established by researchers in high-income countries among populations exposed to civilian forms of trauma. These studies have defined four broad subpopulations according to their trajectories over time, that is, those showing persisting, delayed or late-onset symptoms, recovery and consistently low or no symptoms. $^{8-10}$ It is important to establish whether these trajectories are universally applicable, especially under the specific conditions that pertain to post-conflict countries.

Defining the populations in need of mental health interventions is important in post-conflict countries given the large treatment

\footnotetext{
${ }^{1}$ School of Psychiatry, Psychiatry Research and Teaching Unit, Academic Mental Health Unit, University of New South Wales, Sydney, NSW, Australia; ${ }^{2}$ School of Public Health and Community Medicine, Faculty of Medicine, University of New South Wales, Sydney, NSW, Australia and ${ }^{3}$ Development Policy Center, Australian National University, Canberra, ACT, Australia. Correspondence: Dr AK Tay, Psychiatry Research and Teaching Unit, Academic Mental Health Unit, University of New South Wales, Level 2, Mental Health Centre, Liverpool Hospital, Sydney, NSW 2170, Australia.
}

E-mail: alvin.tay@unsw.edu.au

Received 19 December 2016; revised 29 March 2017; accepted 20 April 2017 
gap in addressing common symptoms of mental distress in the community, ${ }^{11}$ a problem arising from an extreme scarcity of skills and resources. ${ }^{12}$ One partial solution is to apply targeted social programs to problems demonstrated to be the cause of ongoing distress, for example, insecure employment and access to health care. Access to these social goods may have a more general effect of increasing a sense of security and hope for the future, an ethos that is important to promoting the overall program of recovery and development. ${ }^{13}$ It is noteworthy in that respect, that our analysis of the large baseline sample from which the present cohort was drawn, ${ }^{14}$ found associations between anxiety and depressive symptoms and a range of potentially modifiable social factors such as ongoing food insecurity, loss of jobs, lack of access to basic services and concerns about safety. Only a longitudinal study, however, is capable of assessing the influence of these factors on the trajectory of anxiety and depressive symptoms over time, thereby providing more definitive guidance in pinpointing social programs and interventions that may mitigate adverse mental health outcomes in these settings.

An important consideration in undertaking epidemiological studies is to ensure that the measures used can be adopted in routine public health services for screening, selection of high-risk groups, and ongoing monitoring. Clearly, the shorter the screening measures, the more readily they are applied in busy service environments and the more likely there will be adherence by both practitioners and patients. In that regard, it remains to be clarified whether instruments that contain lists of both common depressive and anxiety symptoms are necessary to achieve the outcome of defining persons in distress. In cross-sectional studies, symptoms of anxiety and depression commonly overlap; ${ }^{15}$ it may also be the case that there is a pattern of transition from one symptom pattern to the other over time. ${ }^{7,16}$ If so, it may be sufficient to measure one domain only, for example, symptoms of depression, allowing inferences to be drawn about the likely prevalence and trajectory of anxiety. Our longitudinal study offers the opportunity to examine this issue further.

Debate has persisted as to which factors exert the greatest influence on mental health in post-conflict settings, the chief competing candidates being exposure to past traumas ${ }^{17,18}$ and the ongoing stressors in the post-conflict environment. ${ }^{19} \mathrm{~A}$ balanced view apportions a role to both factors in shaping mental health outcomes, $5,20,21$ a position that suggests that each needs to be considered in identifying persons at risk of ongoing distress and in designing policies and practices aimed at advancing emotional recovery among survivor populations. In undertaking epidemiological studies in Sri Lanka, it is essential to take into account heterogeneity in the ethnic and cultural backgrounds of the constituent population. The Sinhalese represent the majority (74\% of the population), Tamils comprising the largest minority (12\%). Smaller groups include Indian Tamils (6\%) who are distinct from the long-term resident population and Sri Lankan Muslims/ Moors (9\%). ${ }^{22}$

The present analysis of a 12-month follow-up study in Sri Lanka aims to test a number of hypotheses: (1) that a readily interpretable pattern of symptom trajectories can be identified, namely, persisting high, persisting low, recovery and new onset; (2) that past trauma exposure and ongoing adversities influence these trajectories in a manner that is consistent with theoretical expectations and the potential to identify groups in greatest need of mental health attention; (3) that predictors of the poorer outcome trajectories may include potentially modifiable factors, such as employment security and access to health care, that are amenable to be addressed by progressive social and public health policies and programs; and (4) that anxiety and depressive symptoms tend to show a heterotypic pattern (that is a high level of comorbidity and transition from one constellation to the other) over time, suggesting the possibility that public health screening for one constellation may be adequate.

\section{MATERIALS AND METHODS}

Context

Sri Lanka is representative of a country recovering from a long period of conflict and mass trauma. The protracted civil war (1983-2009) led to extensive although uneven exposure to trauma and displacement across the population. Military action involving opposing armed forces of the government (GoSL) and the Liberation Tigers of Tamil Eelam (LTTE) resulted in widespread physical injuries and deaths, mass displacement of whole populations, and associated deprivation of food, water and medical care. ${ }^{23}$ In the later period of conflict, the LTTE achieved control of territories in the north-eastern region of the country, forming a de facto state with its administrative capital in Kilinochchi. By escalating its military activity, GoSL regained control of the north, the intensity of the warfare resulting in the mass displacement of virtually all civilians of the former LTTE controlled areas (Mullativu, Killinochi). ${ }^{24}$ Within 3 years after the cessation of conflict, in which GoSL regained control over the entire disputed territory, over a quarter million of internally displaced persons were returned to their homes. ${ }^{25}$

\section{Sample}

Details of the baseline study have been published elsewhere. ${ }^{14}$ In summary, the baseline survey conducted in 2014 recruited a nationally representative sample of the adult population $(n=20632)$ of Sri Lanka. The mental health measure (see hereunder) comprised a discrete subcomponent of the study, the broader survey focusing on determining the migration intentions of the population, that is, defining the sociodemographic characteristics of those who wished to remain in the country or emigrate, the aim being to attempt to address the factors that were compelling the latter to leave their homeland. In relation to the present analysis, the important finding in our preliminary analysis was that there was no difference on our primary mental health measure between the population subgroups expressing an intent to emigrate or to remain in Sri Lanka.

The follow-up survey of a structured subsample $(n=5136)$ drawn from the baseline sample was conducted in 2015. All analyses on that subsample reported here were weighted (see details hereunder) to ensure that the follow-up sample was representative of the larger baseline population.

In relation to the details of our sampling approach, we applied a multistage sampling design to recruit the baseline group, covering (1) all districts of Sri Lanka that were exposed to mass conflict $(n=8)$; (2) Colombo, the capital; and (3) nine districts randomly selected from the remaining 16 not exposed to conflict. Sampling units were selected the second lowest administrative level (Grama Sevaka, DS) using the probability proportional to size (PPS) method based on national census data gathered in 2012. Eight DSs were selected for large districts and four for small districts (smaller districts were defined as those with fewer than, 4 DSs and less). Next, we selected units of the lowest administrative level (Grama Niladari, GN), using probability proportion to size method. Within large districts, eight DSs were surveyed and five GNs were surveyed within each DS. However, within smaller districts (i.e. those that had less than eight DSs in total), four DSs were surveyed and ten GNs were surveyed in each DS. Houses within each GN were divided into blocks of three, where one house in each block was selected at random until 28 were selected. The baseline response rate from the 26600 people approached was $81 \%$.

The follow-up survey was structured to include 2500 randomly selected persons from 2982 who expressed an intention to emigrate at baseline and 3500 of 17151 who had no intention to emigrate. Of these 6000 persons approached at follow-up, 5136 were re-interviewed in 2015, a response rate of $86 \%$. Non-participants were almost always those who could not be re-contacted because they had relocated.

From the follow-up sample, we identified 1275 respondents residing in the four severe conflict zones included in the study: Mannar, Killinochi, Mullaitivu and Jaffna. Severe exposure was defined by two criteria: heavily and directly impacted by warfare between January 2008 and May 2009 (the final campaign of the war), and levels of population displacement $>75 \%$. In addition, because of its extensive exposure to warfare and displacement over time, Jaffna was included ${ }^{26}$ (see Table 1 for the distribution of respondents across each conflict zone).

\section{Measures}

Symptoms of depression and anxiety. Anxiety and depressive symptoms were assessed at baseline and follow-up using the Hopkins Symptoms Checklist (HSCL-25), ${ }^{27}$ a 25 -item cross-culturally validated measure of 
Table 1. Socio-demographic and mental health characteristics of the follow-up sample $(n=1275)$

\begin{tabular}{|c|c|c|c|c|}
\hline & $\begin{array}{c}2014 \\
(\mathrm{n}=1275)\end{array}$ & $\%$ & $\begin{array}{c}2015 \\
(n=1275)\end{array}$ & $\%$ \\
\hline \multicolumn{5}{|l|}{$\operatorname{Sex}^{a}$} \\
\hline Male & 344 & 27 & 344 & 27 \\
\hline Female & 930 & 73 & 930 & 73 \\
\hline \multicolumn{5}{|l|}{ Age group (years) } \\
\hline$\geqslant 60$ & 163 & 12.8 & 190 & 14.9 \\
\hline $51-60$ & 197 & 15.5 & 204 & 16 \\
\hline $41-50$ & 242 & 19 & 241 & 18.9 \\
\hline $31-40$ & 359 & 28.2 & 364 & 28.6 \\
\hline $18-30$ & 314 & 24.6 & 276 & 21.7 \\
\hline \multicolumn{5}{|l|}{ Marital status $^{b}$} \\
\hline Married & 1150 & 90.3 & 1159 & 91 \\
\hline $\begin{array}{l}\text { Never married (single/ } \\
\text { other) }\end{array}$ & 124 & 9.7 & 115 & 9 \\
\hline \multicolumn{5}{|c|}{ Highest level of educational attainment ${ }^{c}$} \\
\hline None & 14 & 1.1 & 19 & 1.5 \\
\hline $\begin{array}{l}\text { Completed primary } \\
\text { education }\end{array}$ & 348 & 27.3 & 429 & 33.7 \\
\hline Completed high school & 878 & 68.9 & 799 & 62.7 \\
\hline $\begin{array}{l}\text { Completed university } \\
\text { or tertiary }\end{array}$ & 34 & 2.7 & 27 & 2.1 \\
\hline \multicolumn{5}{|l|}{ Mental health outcomes ${ }^{d}$} \\
\hline Depression $(\geqslant 2.2)$ & 557 & 43.8 & 323 & 25.4 \\
\hline Anxiety $(\geqslant 2.2)$ & 313 & 24.6 & 277 & 21.7 \\
\hline \multicolumn{5}{|l|}{ Ethnicity } \\
\hline Tamils & 1184 & 92.9 & 1184 & 92.9 \\
\hline Moors & 90 & 7.1 & 90 & 7.1 \\
\hline \multicolumn{5}{|c|}{ No. of respondents in four severe conflict zones in the northern SL } \\
\hline Mannar & 301 & 23.6 & 301 & 23.6 \\
\hline Killinochi & 314 & 24.6 & 314 & 24.6 \\
\hline Mullaitivu & 307 & 24.1 & 307 & 24.1 \\
\hline Jaffna & 353 & 27.7 & 353 & 27.7 \\
\hline
\end{tabular}

depression and anxiety symptoms used extensively among post-conflict and refugee populations worldwide. ${ }^{28}$ The HSCL-25 has been translated into Tamil for a study in the north of Sri Lanka ${ }^{29}$ and among asylum seekers in Australia. ${ }^{30,31}$ We translated the measure into Sinhalese. Translations followed accepted international procedures for translation and back translation. ${ }^{32}$ Previous psychometric testing of the HSCL across culturally distinct populations from Sub-Saharan Africa, ${ }^{33}$ Eastern Europe ${ }^{34}$ and Asia ${ }^{35-38}$ yielded sound internal consistency (Cronback's alpha $\geqslant 0.90$ for the entire scale; $\geqslant 0.85$ for the depression subscale, $\geqslant 0.76$ for the anxiety subscale), inter-rater reliability (intra-class $r \geqslant 0.80$ ), and test-retest reliability $(\geqslant 0.80)$ for the scale as a whole. Respondents rated each symptom according to the conventional four-point frequency scale ( $1=$ not at all, $2=$ a little, $3=$ quite a lot, $4=$ extremely). In the baseline study, the HSCL-25 was tested for its ease of administration in a pilot study of 1000 persons drawn from all relevant ethnic groups. In addition, we found a sound level of test-retest reliability for the HSCL-25 among a random subsample $(n=1000)$ of respondents from the present sample reinterviewed following the full survey (depression subscale: Kappa $=0.80$; anxiety subscale: Kappa $=0.85$; full measure: 0.89 ). We defined 'symptomatic depression' and 'symptomatic anxiety' according to the conventional international cut-off scores of $>1.75$ for each subscale.

\section{Exposure to traumatic events}

Constraints in the duration of assessments limited inclusion in the baseline study of the HSCL-25 only as a measure of mental health (depression and anxiety). At follow-up, however, we were able to extend the mental health component to assess 21 potential traumatic events drawn from the Harvard Trauma Questionnaire and modified to the context of Sri Lanka. ${ }^{39}$ Items included political imprisonment, assault, torture, witnessing murder, exposure to atrocities and combat situations, sexual violation, losses of family or close others, and severe deprivation of shelter, food, water and medical care for self or others. A trauma count was generated by assigning a score of 1 for each endorsed potential traumatic event type.

\section{Ongoing adversities}

Based on knowledge within the team and available sources, DJ devised questions assessing exposure to a wide range of stresses, including potential threatening conditions and ongoing adversities consistent with the contemporary political and historical context of the country. Focus groups involving community participants endorsed the relevance of items assessing threatening conditions and ongoing adversities (including shortage of food, job loss, access to healthcare and safety in the community). In our baseline survey, respondents provided categorical responses (yes/no) to a list of items detailing these events/conditions in the previous 2 years (2012-2014). At follow-up, we inquired whether participants had experienced the listed stressors during the year between surveys (2014-2015). In our analysis, we applied only items related to ongoing adversities. Based on these data, we generated a binary variable for limited access to healthcare. We also derived a total trauma count by adding the endorsed events (each scored 0 or 1 ) based on the Harvard Trauma Questionnaire list that reflected the major traumas experienced during the extensive civil war.

\section{Personnel and training}

Members of the research team trained local field workers $(n=83)$ in applying the measures using an electronic platform. Interviews were conducted in the home language (either Sinhala or Tamil) in strict privacy and responses were entered directly into tablet devices. Data were accessed daily by the lead survey manager alone.

\section{Ethics}

Ethical permission was granted for the present study by the Australian National University Human Ethics Committee (protocol number 2013/677) and by the Ethics Review Committee of the Faculty of Medicine, University of Colombo, Sri Lanka (EC-16-121). Oral consent was obtained from respondents given reluctance by some participants (identified in piloting) to provide written consent.

\section{Statistical analysis}

We excluded records with extensive missing data $(n=650)$, resulting in a final analytic sample of 4486 persons. From that pool, we identified a subsample $(n=1275)$ of all respondent residents in four severe conflict districts (Mannar, Killinochi, Mullaitivu and Jaffna) for the present analysis. All analyses were based on an adjusted follow-up sample in which sampling weights corrected for stratification and clustering. The sampling weights ensured that the follow-up sample was representative of the baseline sample in relation to fixed and time-variant characteristics (sex, age, marital status, education levels, number of household members and depression/anxiety scores indexed by the Hopkins Symptoms Checklikst25); and that the follow-up sample was adjusted for non-response and clustering.

We applied McNemar's test to assess for differences in prevalence of anxiety and depressive symptoms between baseline and follow-up. We tested two cross-sectional latent class analysis (LCA) models to identify subpopulations with distinctive patterns of anxiety and depressive symptoms (and their combination) at baseline and follow-up. We followed convention by increasing the number of classes serially, examining conventional model-fit indicators using the Bayesian Information Criterion (BIC), sample size-adjusted Bayesian Information Criterion (SS-BIC) and the Akaike's Information Criterion (AIC). ${ }^{40,41}$ Lower values of these indicators suggest a better fit in comparing successive latent class models. In addition, we applied the Vuong-Lo-Mendell-Rubin (VLMR) and the LoMendell-Rubin (LMR) adjusted likelihood ratio tests that compare the fit of a latent class model of $n$ classes to one with $n+1$ classes. ${ }^{42}$ In making an overall judgement concerning the best fitting model, we took into account the principles of parsimony and interpretability (according to the existing data and theory), the degree of class separation, entropy (classification 
quality) and the homogeneity of item conditional probabilities within classes. ${ }^{41}$

We then used unconditional latent transition analysis (LTA) to examine the trajectories of symptoms over time. The measurement component of the LTA identifies whether homogeneous classes can be identified based on symptom patterns at each time point, whereas the structural (autoregressive) component identifies the pattern of transitioning of persons from one symptom class to another over time. ${ }^{43,44}$

We used likelihood ratio tests to compare a model in which all parameter estimates (thresholds) were held equal within classes across time with one in which thresholds were allowed to vary. To account for potential classification errors in the longitudinal LTA model, we used log ratios based on the most likely class memberships obtained from each cross-sectional LCA. ${ }^{45,46}$ LTA analysis produced 16 longitudinal classes; because of low representation in several longitudinal classes, we combined classes into rational groupings relevant to clinical and public health translational priorities.

In the final step, in multinomial logistic regression analysis, we entered relevant variables to predict the derived trajectories, based on three sequential entry blocks ((1) socio-demographic characteristics; (2) trauma exposure; and (3) ongoing adversities including shortage of food, loss of jobs, limited access to healthcare and safety in the community). In the analysis, the low-symptom trajectory was used as the reference group. The analyses were performed in STATA version $14^{\text {[ref. } 47]}$ and Mplus version $7 .^{48}$

\section{RESULTS}

Socio-demographic characteristics

Table 1 reports the socio-demographic characteristics of the analytic cohort as it changed over time. The mean age increased from 41.8 (s.d. $=0.21$ ) to 42.9 (s.d. $=0.21$ ). Rates of marriage and education also increased slightly at follow-up. There was an overall reduction in depression and anxiety symptoms from baseline to follow-up. Closer analysis showed that this reduction involved the majority of individual symptoms of depression and anxiety over time (Table 2).

\section{Cross-sectional LCA}

Table 3 documents the findings of the LCA models conducted to identify subpopulations with differential patterns of anxiety and depressive symptoms at each time point. A three-class model provided the best fit at baseline as indicated by lower values of $\mathrm{BIC}, \mathrm{SS}-\mathrm{BIC}$ and AIC for that model compared to the preceding two-class model. Although the VLMR and LMR indicated statistical improvement for the addition of a fourth class, there was no increase in entropy over the three-class solution. At follow-up, a comparable three-class model was identified, supported by lower values of BIC, SS-BIC and AIC. Figure 1 presents item probabilities for depression and anxiety symptoms for the three-class LCA models at baseline and follow-up. As can be seen, the model produced a comorbid class (presence of both anxiety and depressive symptoms), a depression class and a low-symptom class.

\section{Longitudinal LTA}

An unconditional longitudinal LTA comparing a restricted model (in which thresholds were held equal across the baseline and follow-up LCA models) with the unrestricted model (in which all parameter estimates were allowed to vary) indicated no significant difference in fit between the two (log-likelihood difference $=1546$, $\mathrm{df}=308, P=5.45$ ). Table 4 presents the unconditional transitional probabilities estimated for the three-class longitudinal LTA model.

Given that several of the transitional classes comprised only a small proportion $(<7 \%)$ of the full sample, we aggregated relevant classes into a smaller number of meaningful composite trajectories (Table 5). These comprised a persisting trajectory ( $n=555,43.5 \%)$, which included those assigned to one of the two comorbid classes (depression, comorbid) at both baseline and follow-up; a recovery trajectory $(n=299,23.5 \%)$ (defined by assignment to a morbid class at baseline but to the low-symptom
Table 2. Prevalence of symptoms of anxiety and depression at T1 (2014) and T2 (2015) among the Sri Lankan cohort $(n=1275)$

\begin{tabular}{|c|c|c|c|c|c|}
\hline & \multicolumn{2}{|c|}{ T1 (2014) } & \multicolumn{2}{|c|}{ T2 (2015) } & \multirow[t]{2}{*}{ P-value ${ }^{a}$} \\
\hline & $\mathrm{N}$ & $\%$ & $\mathrm{~N}$ & $\%$ & \\
\hline \multicolumn{6}{|l|}{ Anxiety symptoms } \\
\hline Suddenly scared for no reason & 219 & 17.38 & - & - & $<0.001$ \\
\hline Feeling fearful & 356 & 28.25 & 357 & 28.33 & 0.040 \\
\hline $\begin{array}{l}\text { Faintness, dizziness or } \\
\text { weakness }\end{array}$ & 545 & 43.25 & 476 & 37.78 & $<0.001$ \\
\hline $\begin{array}{l}\text { Nervousness or shakiness } \\
\text { inside }\end{array}$ & 443 & 35.16 & 406 & 32.22 & $<0.001$ \\
\hline Heart pounding or racing & 380 & 30.16 & 363 & 28.81 & 0.002 \\
\hline Trembling & 433 & 34.37 & 414 & 32.86 & $<0.001$ \\
\hline Feeling tense or keyed up & 404 & 32.06 & 378 & 30 & $<0.001$ \\
\hline Headaches & 767 & 60.87 & 706 & 56.03 & $<0.001$ \\
\hline Spells of terror or panic & 47 & 3.73 & 144 & 11.43 & $<0.001$ \\
\hline Feeling restless, can not sit still & 275 & 21.83 & 254 & 20.16 & 0.079 \\
\hline \multicolumn{6}{|l|}{ Depressive symptoms } \\
\hline $\begin{array}{l}\text { Feeling low in energy-slowed } \\
\text { down }\end{array}$ & 521 & 41.35 & 505 & 40.08 & $<0.001$ \\
\hline Blaming yourself for things & 338 & 26.83 & 254 & 20.16 & 0.198 \\
\hline Crying easily & 474 & 37.62 & 457 & 36.27 & $<0.001$ \\
\hline $\begin{array}{l}\text { Loss of sexual interest or } \\
\text { pleasure }\end{array}$ & 114 & 9.05 & 147 & 11.67 & $<0.001$ \\
\hline Poor appetite & 421 & 33.41 & 465 & 36.9 & $<0.001$ \\
\hline $\begin{array}{l}\text { Difficulty falling asleep, staying } \\
\text { asleep }\end{array}$ & 498 & 39.52 & 514 & 40.79 & $<0.001$ \\
\hline $\begin{array}{l}\text { Feeling hopeless about the } \\
\text { future }\end{array}$ & 298 & 23.65 & 266 & 21.11 & 0.531 \\
\hline Feeling blue & 787 & 62.46 & 695 & 55.16 & $<0.001$ \\
\hline Feeling lonely & 499 & 39.6 & 410 & 32.54 & $<0.001$ \\
\hline Feeling trapped or caught & 56 & 4.44 & 134 & 10.63 & $<0.001$ \\
\hline $\begin{array}{l}\text { Worrying too much about } \\
\text { things }\end{array}$ & 713 & 56.59 & 469 & 37.22 & $<0.001$ \\
\hline Feeling no interest in things & 246 & 19.52 & 273 & 21.67 & 0.002 \\
\hline Thoughts of ending your life & 89 & 7.06 & 150 & 11.9 & $<0.001$ \\
\hline Feeling everything is an effort & 1225 & 97.22 & 1121 & 88.97 & $<0.001$ \\
\hline Feelings of worthlessness & 1139 & 90.4 & 1077 & 85.48 & $<0.001$ \\
\hline
\end{tabular}

class at follow-up), an incident trajectory ( $n=170,13.3 \%)$ (those transitioning from the low-symptom class at baseline to one of the two morbid classes at follow-up); and a low-symptom trajectory $(n=251,19.7 \%)$ (those remaining in the low-symptom class at both time points). The longitudinal transition patterns from baseline to follow-up are depicted in Figure 2.

\section{Class stability and transitional probability}

Transitional probabilities can be interpreted as the probability of remaining in the same latent class (as indicated by diagonals in Table 4) from baseline to follow-up, and the probability of transitioning from one latent class to another over time, represented by off-diagonal probabilities.

Individuals assigned to the comorbid and depression classes at baseline exhibited moderate probabilities $(>0.30)$ of remaining in their respective classes at follow-up. The low-symptom class showed the largest class stability indicated by a moderate-to-high probability $(>0.60)$ of remaining in that class over time.

Off-diagonal probabilities indicate that individuals transitioning from the comorbid class at baseline to a different class at followup had similar and mid-range $(>0.2-0.5)$ probabilities of transitioning into the depression class and the low-symptom class, respectively (Table 4). Individuals in the depression class had 
Table 3. Goodness-of-fit statistics for cross-sectional latent class analysis of symptoms of anxiety and depression at baseline and 12-month follow-up

\begin{tabular}{|c|c|c|c|c|c|c|c|c|c|c|}
\hline Model tested & $F P$ & $L R \times 2$ & $B I C$ & $S S A-B I C$ & $A I C$ & Entropy & $V L M R$ & $\mathrm{P}$ & $L M R$ & $P$ \\
\hline 1 Class & 25 & -16718.95 & 33616.66 & 33537.25 & 33487.89 & - & - & - & - & - \\
\hline 3 Class & 77 & -13251.653 & 27053.91 & 26809.32 & 26657.31 & 0.90 & -13957.57 & $<0.001$ & 1404.08 & $<0.001$ \\
\hline 4 Class & 103 & -12740.41 & 26217.34 & 25890.16 & 25686.81 & 0.90 & -13251.65 & $<0.001$ & 1017.02 & $<0.001$ \\
\hline \multicolumn{11}{|l|}{ Time 2 (2015) } \\
\hline 3 Class & 77 & -12278.75 & 25108.11 & 24863.52 & 24711.51 & 0.94 & -13268.45 & $<0.001$ & 1968.80 & $<0.001$ \\
\hline 4 Class & 103 & -12278.75 & 25108.11 & 24863.52 & 24711.51 & 0.94 & -13268.45 & $<0.001$ & 1968.80 & $<0.001$ \\
\hline
\end{tabular}

Abbreviations: AIC, Akaike information criterion; BIC, Bayesian information Criterion; FP, free parameters; LMR, Lo-Mendell-Rubin-adjusted likelihood ratio test; LR $X^{2}$, likelihood ratio chi square; SSA-BIC, sample size-adjusted BIC; VLMR, Vuong-Lo-Mendell-Rubin likelihood ratio test. The bold values indicate the bestfitting 3-class solution.
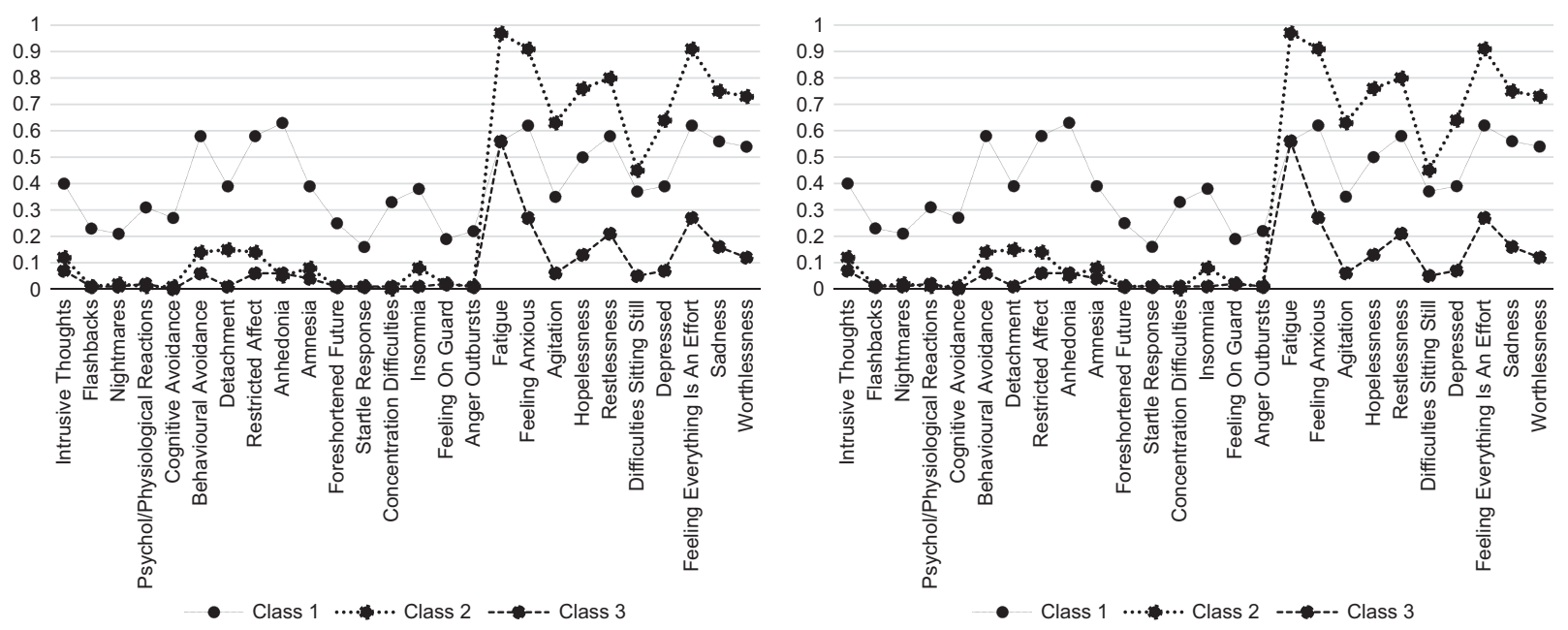

Figure 1. Posterior probabilities for cross-sectional latent class models at baseline (left) and follow-up (right) among a cohort of 1275 respondents.

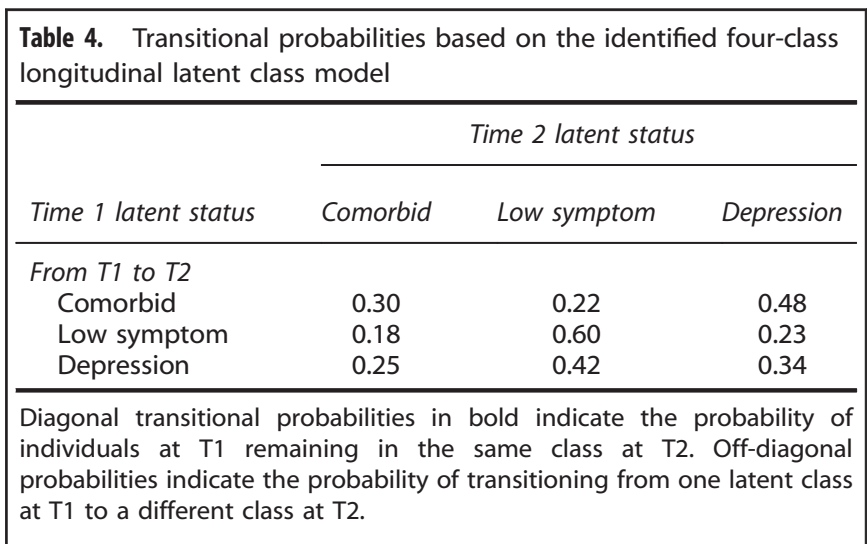

a slightly higher probability of transitioning to the low-symptom class, compared to remaining in the same class or transitioning to the comorbid class at follow-up. Those in the baseline low-symptom class were more likely to remain in that class than transitioning into the comorbid class or depression class at follow-up. Table 5 reports transitional latent class proportions based on the longitudinal LTA model. Specifically, most persons in a symptomatic class at baseline (that is, assigned to the depression or comorbid class) remained in one of those morbid classes at follow-up.

Multivariate associations between socio-demographic characteristics, traumatic exposure and ongoing adversities with longitudinal class membership.

Table 6 details associations found between follow-up sociodemographic factors, trauma exposure, ongoing adversities and the symptom trajectories, the low-symptom (class 4, 19.7\%) acting as the reference class in all comparisons. In relation to baseline socio-demographic characteristics, the persisting and incident (new onset) trajectory groups contained a larger portion of women (persisting: $\mathrm{OR}=1.79,95 \% \mathrm{Cl}=1.20-2.69$; incident: $\mathrm{OR}=$ 1.82, $\mathrm{Cl}=1.19-2.78)$. In relation to traumatic exposure, the persisting and incident groups, reported greater exposure to conflict-related traumatic events (persisting: $\mathrm{OR}=1.18, \mathrm{Cl}=1.13-$ 1.23; incident: $\mathrm{OR}=1.24, \mathrm{Cl}=1.19-1.29$ ). In relation to ongoing adversities, both the persisting and incident groups were more likely to report lack of access to healthcare (persisting: $\mathrm{OR}=2.10$, $\mathrm{Cl}=1.29-3.29$; incident: $\mathrm{OR}=2.40, \mathrm{Cl}=1.41-4.18$ ); and the persisting group was exceptional in the high rate of job loss reported 
Table 5. Transitional class proportions from time 1 to time 2 based on the estimated longitudinal latent transition analysis

\begin{tabular}{lllll}
\hline LTA class & Time 1 & \multicolumn{1}{c}{ Time 2 } & N (n= 1275) \\
\hline 1 & Class 1 (comorbid) & Class 1 (comorbid) & $79(0.06)$ & Trajectory \\
2 & Class 1 (comorbid) & Class 2 (low symptom) & $53(0.04)$ & Persistent (P) \\
3 & Class 1 (comorbid) & Class 3 (depression) & $135(0.11)$ & Recovery (R) \\
4 & Class 2 (low symptom) & Class 1 (comorbid) & $76(0.06)$ & Persistent (P) \\
5 & Class 2 (low symptom) & Class 2 (low symptom) & $251(0.20)$ & Low symptom (L) \\
6 & Class 2 (low symptom) & Class 3 (depression) & $94(0.07)$ & Incident (I) \\
7 & Class 3 (depression) & Class 1 (comorbid) & $148(0.12)$ & Persistent (P) \\
8 & Class 3 (depression) & Class 2 (low symptom) & $246(0.19)$ & Recovery (R) \\
9 & Class 3 (depression) & Class 3 (depression) & $193(0.15)$ & Persistent (P) \\
\hline
\end{tabular}

Note: derivation of four rational trajectories based on the longitudinal transition classes: (1) persistent trajectory $=($ LTA classes $1+3+7+9=555,43.5) ;(2)$ recovery trajectory $=($ LTA classes $2+8=299,23.5)$; ( 3$)$ incident trajectory $=($ LTA classes $4+6=170,13.3) ;(4)$ low-symptom trajectory $=($ LTA class $5=251,19.7)$.

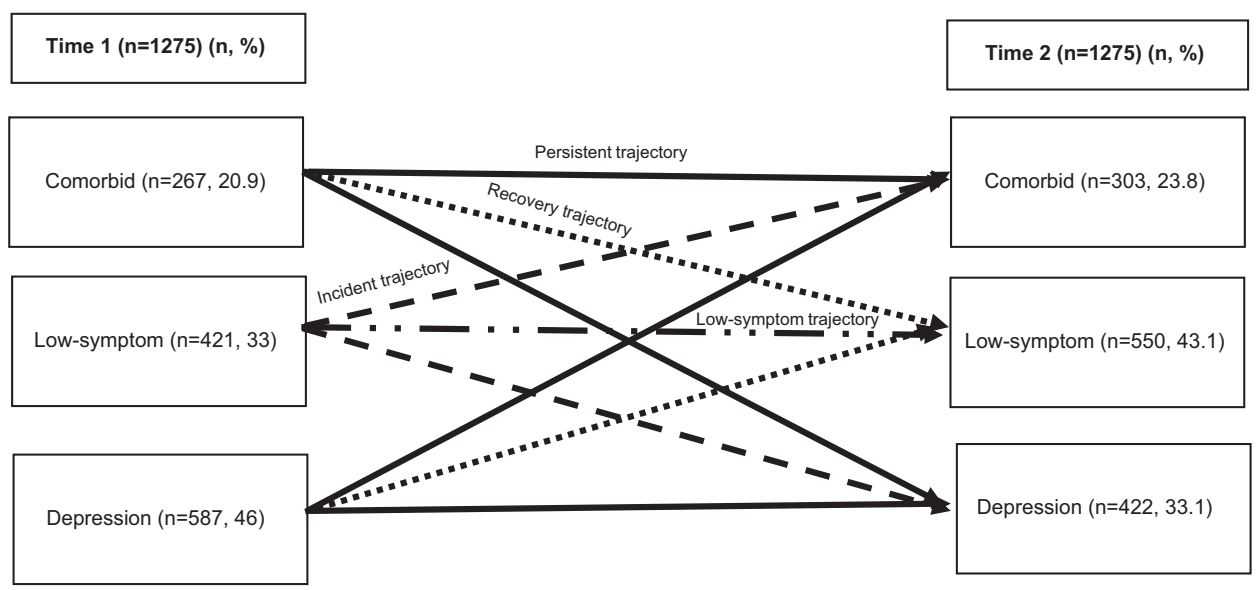

Figure 2. Longitudinal transitional patterns from time 1 to time 2 and derivation of four core symptom trajectories $(n=1275)$.

$(\mathrm{OR}=1.77, \mathrm{Cl}=1.23-2.55)$. The recovery group was characterized by an absence of risk factors and the inclusion of a greater number of older men (>40 years), compared to the low-symptom trajectory.

\section{DISCUSSION}

Our analysis identified meaningful trajectories of depression and comorbid anxiety and depressive symptoms over a 1-year period among a large cohort exposed to severe mass conflict, concluding 6 years earlier. There are several notable findings from our analysis: that, in general, symptoms of anxiety and depression showed improvement over a short period of time (1 year) of follow-up; that, nevertheless, almost a half of the sample showed a persistence in symptoms; that symptom trajectories derived corresponded broadly with patterns identified in other postconflict $^{49}$ and trauma-affected populations; ${ }^{10}$ and that both past trauma exposure and ongoing adversities including lack of access to healthcare as well as loss of jobs were associated with poor outcome symptom trajectories over the course of follow-up.

Before discussing our findings, we consider the strengths and limitations of the study. Our study is unique in some of its key characteristics: the inquiry is the largest follow-up investigation of its kind in the contemporary post-conflict field; the baseline sample was representative of the national population and the follow-up sample was structured and weighted to maintain its representative nature; we applied modern statistical modeling to derive trajectories of anxiety depression; and we examined key psychosocial variables that shaped these outcomes with an explicit eye on the translational implications of the findings. In relation to sampling, we drew on a nation-wide survey of Sri Lankan populations employing a multi-staged random sampling design across 25 districts, achieving a high response rate at baseline and a good retention rate (86\%) at follow-up. We weighted the follow-up sample accordingly to ensure it retained its representativeness of the base population in relation to key socio-demographic characteristics and mental health indices, thereby ensuring the validity of the longitudinal inquiry of follow-up.

Limitations of the study are that the mental health component was an addition to the primary objective of the study which was to characterize persons intending and not intending to emigrate from Sri Lanka. However, as indicated, we adjusted for possible sampling biases taking into consideration potential group differences between individuals who intended to migrate and those who did not. In addition, sub-group analysis indicated no significant differences in mental health outcomes between the two migration intention groups.

In order to establish the generalizability of our findings, replication in other post-conflict contexts and cultures worldwide will be necessary. The HSCL-25 has been used previously in Sri Lanka $^{29}$ and in a wide range of transcultural settings. ${ }^{33,37,50-52}$ Nevertheless, there remains a risk that the measure does not capture culture-specific idioms of distress. Qualitative research may assist in identifying locally salient terms for distress that should be included in the symptom lists for anxiety and depression. In addition, the HSCL-25 requires full recalibration against a gold standard clinical interview in each ethnic 


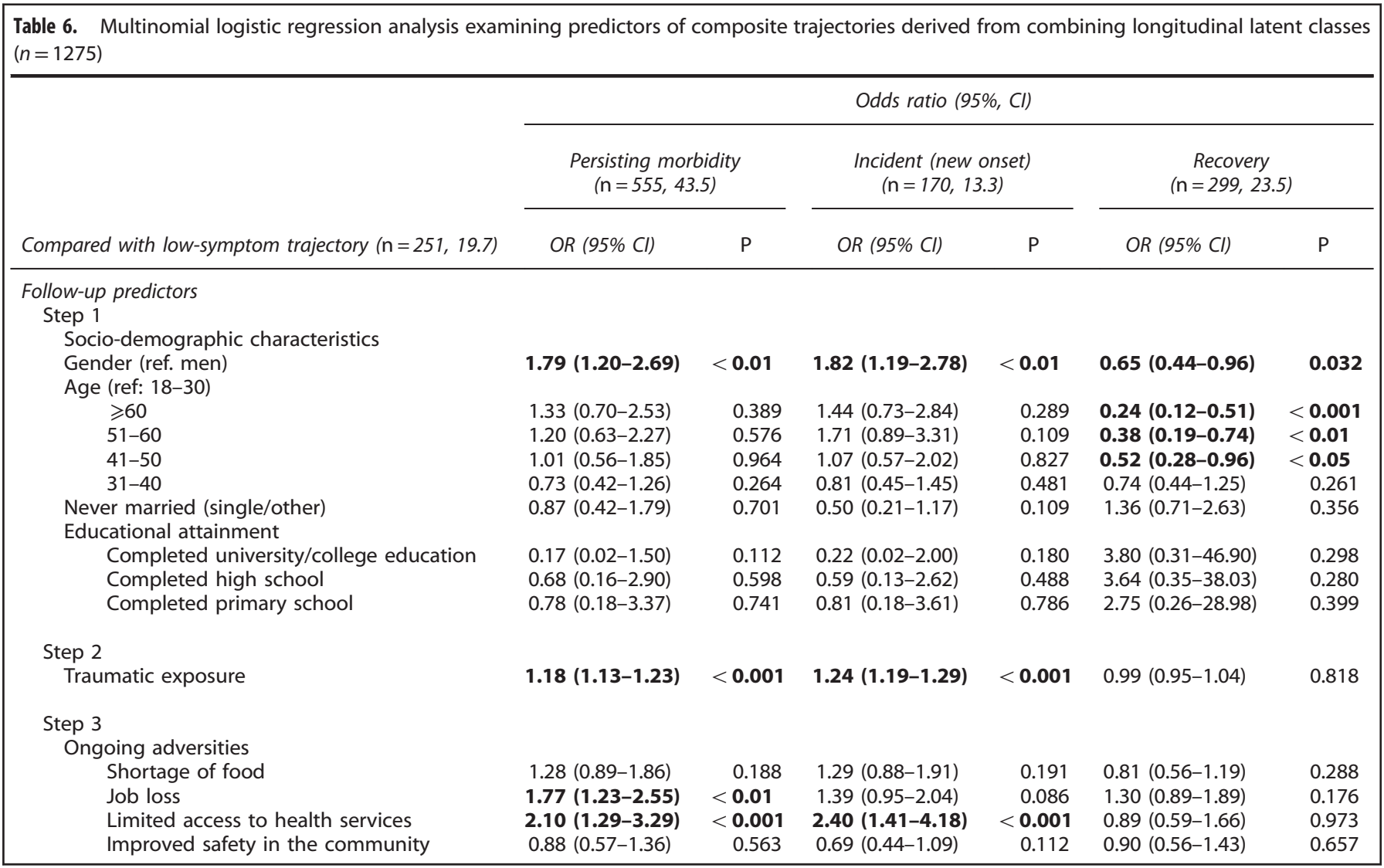

subpopulations studied if inferences are to be drawn about the relevance of our findings to the presence or absence of probable psychiatric diagnoses. Nevertheless, the brevity of the HSCL provides a strong rationale for including it as a broad screening measure for distress in nation-wide surveys in post-conflict countries. Focusing on general symptoms of anxiety and depression over the past 4 weeks is likely to have improved accuracy of recall but the time restriction prevented us from determining the longer-term course of symptoms. As such, we cannot determine whether the so-named persisting class experienced chronic, fluctuating or a recurrence of symptoms from baseline to follow-up. Reports of trauma may be subject both to anamnestic bias and distortions arising from the suppression of traumatic memories. Notwithstanding, we note that the pattern of traumas documented across the sample as a whole is consistent with the known history of conflict in Sri Lanka. ${ }^{23,29}$ Our longitudinal analysis traced the symptom trajectories of depression and anxiety; future studies are needed to examine the course of symptoms of other comorbid disorders such as post-traumatic stress disorder. Finally, we cannot be certain of cause-effect relationships in all instances. For example, it is possible that loss of a job is an outcome rather than a cause of depression, or there may be a complex interaction between the two.

In spite of these caveats, our findings advance knowledge in the field by supporting a rational typology of trajectories of symptoms of anxiety and depression over time. There was a notable similarity in our typology of trajectories and those observed among survivors of mass conflict in a different setting, Timor-Leste, ${ }^{49}$ as well as among survivors of natural disasters and accidents in highincome countries. ${ }^{16}$ In addition, our findings support the potential influence of a range of experiences and conditions (past trauma, ongoing adversity in the form of deprivation of basic services, particularly health care, and opportunities for gainful employment in the post-conflict environment) in shaping general symptom trajectories of anxiety and depression following an extensive period of internecine conflict in Sri Lanka.

Given the logistic difficulties of screening for multiple health problems in routine public health care systems in low-resourced post-conflict countries, an important question for mental health is whether it is necessary to include both symptoms of anxiety and depression, as is the custom. As expected, the McNemar's paired tests we conducted indicated that symptoms of anxiety and depression are closely interrelated, in this instance both at baseline and follow-up. Nevertheless, the transition of individuals across classes over time suggested complex patterns that were partially homotypic (for example, depression at baseline predicting depression at follow-up) and partially heterotypic (for example, individuals in the comorbid class at baseline transitioning to depression at follow-up). In that respect, it is notable that only $15 \%$ of the cohort assigned to the depression class at followup commenced in the same class at baseline; in addition, $11 \%$ who transitioned to the depression class at follow-up were in the comorbid class at baseline. The complexity of these patterns suggests that it may be premature to omit symptoms of anxiety or depression in full in contemporary screening exercises until a better understanding is achieved of the factors that determine the various symptom trajectories involving these two constructs over time.

The finding that both the persisting and incident (new onset) groups included proportionally more women is consistent with the general psychiatric literature on sex differences in anxiety and depression. ${ }^{53-57}$ A surprising finding was that although a large proportion of women in these groups were widows relative to the remainder population, and being a widow in Sri Lanka is known to be associated with high levels of mental distress, ${ }^{25,58,59}$ marital status did not show a significant association with assignment to trajectory groups. The relationship of adverse mental health outcomes with past trauma and ongoing adversity confirms the 
importance of these two components in shaping not only the onset but the persistence of common mental health symptoms. It is possible that the protective aspect of being an older man relates to the ongoing status of this group in Sri Lanka, one that confers advantages (cultural, within the family and the society), that promote the capacity to maintain or restore mental health. The persisting symptom group was the only subpopulation reporting an excess of job losses at follow-up. The pattern observed is consistent with longitudinal data from other countries experiencing extensive persecution. ${ }^{49,60}$ The association should be interpreted with caution given questions of causality as indicated. ${ }^{61,62}$

Our findings indicated that in the Sri Lankan context, the new onset group was characterized by past conflict exposure and lack of access to healthcare. There is a growing body of studies among refugees and post-conflict populations indicating that deprivations associated with access to services and opportunities for advancement are strongly associated with mental disorders including post-traumatic stress disorder, anxiety and depression. ${ }^{63-66}$ Several cross-sectional studies amongst refugees and conflictaffected populations from the Middle East ${ }^{67}$ and Africa ${ }^{68,69}$ have shown that lack of access to services to satisfy basic needs in concert with exposure to traumatic events constitute major contributors to adverse mental health outcomes. The new onset group is of particular interest, given the potential to avert a portion of these incident cases by providing strategic services and opportunities that will maintain morale and a sense of security and hope.

In general, our study suggests the value of undertaking a brief screening of common mental symptoms of anxiety and depression as well as the core modifiable risk factors associated with these adverse outcomes in post-conflict settings such as Sri Lanka. From a translational service planning and policy perspective, our findings reinforce the importance of establishing supportive conditions that allow for health-related, social and economic recovery in the aftermath of prolonged conflict. Specifically, access to services (such as health) and employment security are not only important in their own right in maintaining physical health and reducing poverty, but may be instrumental in improving mental health outcomes by creating a sense of security and hope for the future. In that respect, the provision of services has both a direct and tangible effect but also provides reassurance to the population that the fundamental support systems of stable societies are being re-established, a strong symbol of the prospect of achieving future peace, health and advancement. ${ }^{70}$

\section{CONCLUSIONS}

We found four composite trajectories of anxiety and depression emerging over a 1-year period in a large cohort exposed to severe conflict in Sri Lanka. Specifically, we identified a recovery trajectory, a persistent trajectory, an incident trajectory and a low-symptom trajectory. The persistent and incident trajectories were each associated with past conflict-related trauma exposure and lack of access to services such as healthcare. The persistent trajectory was unique in being associated with greater exposure to loss of jobs at follow-up. The recovery trajectory was characterized by an absence of risk factors at follow-up and with a larger portion of older men failing into this category. Our findings support the importance of providing health care services and employment opportunities not only for their substantive value but also to provide a sense of stability and optimism for the future, vital to alleviating pervasive symptoms of anxiety and depression in a post-conflict society such as Sri Lanka.

\section{CONFLICT OF INTEREST}

The authors declare no conflict of interest.

\section{ACKNOWLEDGMENTS}

We thank all our field personnel who contributed to all aspects of this project. We thank Australian National University for providing financial support.

\section{REFERENCES}

1 Hollifield M, Warner TD, Lian N, Krakow B, Jenkins JH, Kesler J et al. Measuring trauma and health status in refugees: a critical review. JAMA 2002; 288: 611-621.

2 Steel Z, Chey T, Silove D, Marnane C, Bryant RA, Ommeren M. Association of torture and other potentially traumatic events with mental health outcomes among populations exposed to mass conflict and displacement: a systematic review and meta-analysis. J Am Med Assoc 2009; 302: 537-549.

3 Mollica RF, Brooks R, Tor S, Lopes-Cardozo B, Silove D. The enduring mental health impact of mass violence: a community comparison study of Cambodian civilians living in Cambodia and Thailand. Int J Soc Psychiatry 2014; 60: 6-20.

4 Mollica RF, Sarajlić N, Chernoff M, Lavelle J, Vuković IS, Massagli MP. Longitudinal study of psychiatric symptoms, disability, mortality, and emigration among Bosnian refugees. J Am Med Assoc 2001; 286: 546-554.

5 Kohrt BA, Hruschka DJ, Worthman CM, Kunz RD, Baldwin JL, Upadhaya N et al. Political violence and mental health in Nepal: prospective study. $\mathrm{Br} J$ Psychiatry 2012; 201: 268-275.

6 Westermeyer J, Neider J, Callies A. Psychosocial adjustment of Hmong refugees during their first decade in the United states. A longitudinal study. J Nerv Ment Dis 1989; 177: 132-139.

7 Lamers F, Rhebergen D, Merikangas KR, de Jonge P, Beekman AT, Penninx BW. Stability and transitions of depressive subtypes over a 2-year follow-up. Psychol Med 2012; 42: 2083-2093.

8 Salguero JM, Cano-Vindel A, Iruarrizaga I, Fernández-Berrocal P, Galea S. Trajectory and predictors of depression in a 12-month prospective study after the Madrid March 11 terrorist attacks. J Psychiatr Res 2011; 45: 1395-1403.

9 Bryant RA, O'Donnell ML, Creamer M, McFarlane AC, Silove D. A multisite analysis of the fluctuating course of posttraumatic stress disorder. JAMA Psychiatry 2013; 70: 839-846.

10 Bryant RA, Nickerson A, Creamer M, O'Donnell M, Forbes D, Galatzer-Levy I et al. Trajectory of post-traumatic stress following traumatic injury: 6-year follow-up. $\mathrm{Br}$ J Psychiatry 2015; 206: 417-423.

11 Collins PY, Patel V, Joestl SS, March D, Insel TR, Daar AS et al. Grand challenges in global mental health. Nature 2011; 475: 27-30.

12 Patel V. Global mental health: from science to action. Harv Rev Psychiatry 2012; 20: 6-12.

13 Silove D, Steel Z. Understanding community psychosocial needs after disasters: implications for mental health services. J Postgrad Med 2006; 52: 121-125.

14 Jayasuriya D, Jayasuriya R, Tay AK, Silove D. Associations of mental distress with residency in conflict zones, ethnic minority status, and potentially modifiable social factors following conflict in Sri Lanka: a nationwide cross-sectional study. Lancet Psychiatry 2016; 3: 145-153.

15 Steel Z, Chey T, Silove D, Marnane C, Bryant RA, Van Ommeren M. Association of torture and other potentially traumatic events with mental health outcomes among populations exposed to mass conflict and displacement: a systematic review and meta-analysis. JAMA 2009; 302: 537-549.

16 Forbes D, Nickerson A, Alkemade N, Bryant RA, Creamer M, Silove D et al. Longitudinal analysis of latent classes of psychopathology and patterns of class migration in survivors of severe injury. J Clin Psychiatry 2015; 76: 1193-1199.

17 Mollica RF, Sarajlic N, Chernoff M, Lavelle J, Vukovic IS, Massagli MP. Longitudinal study of psychiatric symptoms, disability, mortality, and emigration among Bosnian refugees. JAMA 2001; 286: 546-554.

18 Silove D, Steel Z, Susljik I, Frommer N, Loneragan C, Chey T. The impact of the refugee decision on the trajectory of PTSD, anxiety, and depressive symptoms among asylum seekers: a longitudinal study. Am J Disaster Med 2007; 2: 321-329.

19 Miller KE, Rasmussen A. War exposure, daily stressors, and mental health in conflict and post-conflict settings: bridging the divide between trauma-focused and psychosocial frameworks. Soc Sci Med 2010; 70: 7-16.

20 Tay AK, Rees S, Chen J, Kareth M, Lahe S, Kitau R et al. Associations of conflictrelated trauma and ongoing stressors with the mental health and functioning of West Papuan Refugees in Port Moresby, Papua New Guinea (PNG). PLoS ONE 2015; 10: e0125178.

21 Jordans MJ, Semrau M, Thornicroft G, van Ommeren M. Role of current perceived needs in explaining the association between past trauma exposure and distress in humanitarian settings in Jordan and Nepal. Br J Psychiatry 2012; 201: 276-281.

22 DCS. Population by Ethnic Group, Census Years. Department of Census \& Statistics: Sri Lanka, 2012.

23 Somasundaram DJ. Psychiatric morbidity due to war in Northern Sri Lanka. In: Wilson JP, Raphael B (eds). International Handbook of Traumatic Stress Syndromes, 1993, pp 333-348. 
24 Saparamadu C, Lall A. Resettlement of conflict-induced IDPs in Northern Sri Lanka: political economy of state policy and practice. In: Working Paper 10. Centre for Policy Analysis: Colombo, Sri Lanka, 2014.

25 Siriwardhana C, Adikari A, Pannala G, Siribaddana S, Abas M, Sumathipala A et al. Prolonged internal displacement and common mental disorders in Sri Lanka: the COMRAID study. PLoS ONE 2013; 8: e64742.

26 Raymond M. Scarred communities - psychosocial impact of man-made and natural disasters on Sri Lankan society. Med Confl Surviv 2015; 5: 1-3.

27 Mollica RF, Wyshak G, De Marneffe D. Indochinese versions of the Hopkins Symptom Checklist-25: a screening instrument for the psychiatric care of refugees. Am J Psychiatry 1987; 144: 497-500.

28 Kleijn WC, Hovens JE, Rodenburg JJ. Posttraumatic stress symptoms in refugees: assessments with the Harvard Trauma Questionnaire and the Hopkins symptom checklist-25 in different languages. Psychol Rep 2001; 88: 527-532.

29 Husain F, Anderson M, Lopes Cardozo B, Becknell K, Blanton C, Araki D et al. Prevalence of war-related mental health conditions and association with displacement status in postwar Jaffna District, Sri Lanka. JAMA 2011; 306: 522-531.

30 Silove D, Steel Z, McGorry P, Miles V, Drobny J. The impact of torture on posttraumatic stress symptoms in war-affected Tamil refugees and immigrants. Compr Psychiatry 2002; 43: 49-55.

31 Steel Z, Silove D, Bird K, McGorry P, Mohan P. Pathways from war trauma to posttraumatic stress symptoms among Tamil asylum seekers, refugees, and immigrants. J Trauma Stress 1999; 12: 421-435.

32 Van Ommeren M, Sharma B, Thapa S, Makaju R, Prasain D, Bhattarai R et al. Preparing instruments for transcultural research: use of the translation monitoring form with Nepali-speaking Bhutanese refugees. Transcult Psychiatry 1999; 36: 285-301.

33 Kaaya SF, Lee B, Mbwambo JK, Smith-Fawzi MC, Leshabari MT. Detecting depressive disorder with a 19-item local instrument in Tanzania. Int J Soc Psychiatry 2008; 54: 21-33.

34 Oruc L, Kapetanovic A, Pojskic N, Miley K, Forstbauer S, Mollica FR et al. Screening for PTSD and depression in Bosnia and Herzegovina: validating the Harvard Trauma Questionnaire and the Hopkins Symptom Checklist. Int J Cult Ment Health 2008; 1: 105-116.

35 Silove D, Manicavasagar V, Mollica R, Thai M, Khiek D, Lavelle J et al. Screening for depression and PTSD in a Cambodian population unaffected by war: comparing the Hopkins Symptom Checklist and Harvard Trauma Questionnaire with the structured clinical interview. J Nerv Ment Dis 2007; 195: 152-157.

36 Lhewa D, Banu S, Rosenfeld B, Keller A. Validation of a Tibetan translation of the Hopkins Symptom Checklist-25 and the Harvard Trauma Questionnaire. Assessment 2007; 14: 223-230.

37 Hinton WL, Du N, Chen YC, Tran CG, Newman TB, Lu FG. Screening for major depression in Vietnamese refugees: a validation and comparison of two instruments in a health screening population. J Gen Intern Med 1994; 9: 202-206.

38 Mollica RF, Wyshak G, De Marneffe D, Tu B, Yang T, Khuon F. Hopkins Symptom Checklist (HSCL-25): manual for Cambodian, Laotian and Vietnamese versions. Torture 1996; 6(Suppl. 1): 35-42.

39 Shoeb M, Weinstein H, Mollica R. The Harvard trauma questionnaire: adapting a cross-cultural instrument for measuring torture, trauma and posttraumatic stress disorder in Iraqi refugees. Int J Soc Psychiatry 2007; 53: 447-463.

40 McGCutcheon AC. Latent Class Analysis. Sage: Beverly Hills, CA, 1987.

41 Nylund KL, Asparouhov T, Muthen B. Deciding on the number of classes in latent class analysis and growth mixture modeling: a Monte Carlo simulation study. Struct Equ Modeling 2007; 14: 535-569.

42 Collins LM, Fidler PL, Wugalter SE, Long JD. Goodness-of-fit testing for latent class models. Multivariate Behav Res 1996; 28: 375-389.

43 Collins LM, Lanza ST. Latent Class and Latent Transition Analysis: With Applications in the Social, Behavioral, and Health Sciences. Wiley: NJ, USA, 2009; 330.

44 Nylund KL Latent transition analysis: modeling extensions an an application to peer victimization. PhD thesis, UCLA, USA, 2007.

45 Muthen B. Three-step latent transition analysis. In: Modern Modeling Methods Conference on Mplus. University of Connecticut: CA, 2013, pp 1-15.

46 Muthen B, Asparouhov T. LTA in Mplus: Transition Probabilities Influenced by Covariates. Mplus Web Notes: No. 13, 2011

47 StataCorp. Stata Statistical Software: Release 13. StataCorp LP: College station, TX, USA, 2013.

48 Muthen L, Muthen B. Mplus User's Guide, 7th edn. Muthen \& Muthen: Los Angeles, CA, USA, 2014.

49 Tay AK, Rees S, Steel Z, Tam N, Soares Z, Soares C et al. Six year trajectories of post-traumatic stress and severe psychological distress symptoms and associations with timing of trauma exposure, ongoing adversity and sense of injustice: a latent transition analysis of a community cohort in conflict-affected Timor-Leste. Br Med J Open 2016; 6: 1-11.

50 Glaesmer H, Braehler E, Grande G, Hinz A, Petermann F, Romppel M. The German Version of the Hopkins Symptoms Checklist-25 (HSCL-25) --factorial structure, psychometric properties, and population-based norms. Compr Psychiatry 2014; 55: 396-403.

51 Ventevogel P, De Vries G, Scholte WF, Shinwari NR, Faiz H, Nassery R et al. Properties of the Hopkins Symptom Checklist-25 (HSCL-25) and the Self-Reporting Questionnaire (SRQ-20) as screening instruments used in primary care in Afghanistan. Soc Psychiatry Psychiatr Epidemiol 2007; 42: 328-335.

52 Lavik NJ, Laake P, Hauff E, Solberg $\varnothing$. The use of self-reports in psychiatric studies of traumatized refugees: validation and analysis of HSCL-25. Nord J Psychiatry 1999; 53: 17-20.

53 Gardener EK, Carr AR, Macgregor A, Felmingham KL. Sex differences and emotion regulation: an event-related potential study. PLOS ONE 2013; 8: e73475.

54 Felmingham KL, Tran TP, Fong WC, Bryant RA. Sex differences in emotional memory consolidation: the effect of stress-induced salivary alpha-amylase and cortisol. Biol Psychol 2012; 89: 539-544.

55 Armour C, Elhai JD, Layne CM, Shevlin M, Durakovic-Belko E, Djapo N et al. Gender differences in the factor structure of posttraumatic stress disorder symptoms in war-exposed adolescents. J Anxiety Disord 2011; 25: 604-611.

56 Tolin DF, Foa EB. Sex differences in trauma and posttraumatic stress disorder: quantitative review of 25 years of research. Psychol Bull 2006; 132: 959-992.

57 Kessler RC, Berglund P, Demler O, Jin R, Koretz D, Merikangas KR et al. The epidemiology of major depressive disorder: results from the National Comorbidity Survey Replication (NCS-R). JAMA 2003; 289: 3095-3105.

58 Tambiah Y. Sexuality and women's rights in armed conflict in Sri Lanka. Reprod Health Matters 2004; 12: 78-87.

59 Somasundaram D, Sivayokan S. Rebuilding community resilience in a post-war context: developing insight and recommendations - a qualitative study in Northern Sri Lanka. Int J Ment Health Syst 2013; 7: 3.

60 Silove D, Liddell B, Rees S, Chey T, Nickerson A, Tam N et al. Effects of recurrent violence on post-traumatic stress disorder and severe distress in conflict-affected Timor-Leste: a 6-year longitudinal study. Lancet Global Health 2014; 2: e293-e300.

61 Kaspersen SL, Pape K, Vie GA, Ose SO, Krokstad S, Gunnell D et al. Health and unemployment: 14 years of follow-up on job loss in the Norwegian HUNT Study. Eur J Public Health 2016; 26: 312-317.

62 Milner A, Page A, LaMontagne AD. Cause and effect in studies on unemployment, mental health and suicide: a meta-analytic and conceptual review. Psychol Med 2014; 44: 909-917.

63 Priebe S, Matanov A, Jankovic Gavrilovic J, McCrone P, Ljubotina D, Knezevic G et al. Consequences of untreated posttraumatic stress disorder following war in former Yugoslavia: morbidity, subjective quality of life, and care costs. Croat Med J 2009; 50: 465-475.

64 Brooks R, Silove D, Steel Z, Steel CB, Rees S. Explosive anger in postconflict Timor Leste: interaction of socio-economic disadvantage and past human rightsrelated trauma. J Affect Disord 2011; 131: 268-276.

65 Steel Z, Silove D, Giao NM, Phan T, Chey T, Whelan A et al. International and indigenous diagnoses of mental disorder among Vietnamese living in Vietnam and Australia. Br J Psychiatry 2009; 194: 326-333.

66 Panter-Brick C, Goodman A, Tol W, Eggerman M. Mental health and childhood adversities: a longitudinal study in Kabul, Afghanistan. J Am Acad Child Adolesc Psychiatry 2011; 50: 349-363.

67 Ghattas H, Sassine AJ, Seyfert K, Nord M, Sahyoun NR. Prevalence and correlates of food insecurity among Palestinian Refugees in Lebanon: data from a household survey. PLOS ONE 2015; 10: e0130724.

68 Mugisha J, Muyinda H, Wandiembe $P$, Kinyanda E. Prevalence and factors associated with posttraumatic stress disorder seven years after the conflict in three districts in northern Uganda (The Wayo-Nero Study). BMC Psychiatry 2015; 15: 170.

69 Singh KP, Bhoopathy SV, Worth H, Seale H, Richmond RL. Nutrition among men and household food security in an internally displaced persons camp in Kenya. Public Health Nutr 2016; 19: 723-731.

70 Tay AK, Silove D. The ADAPT model: bridging the gap between psychosocial and individual responses to mass violence and refugee trauma. Epidemiol Psychiatr Sci 2016; 26: 142-145.

This work is licensed under a Creative Commons AttributionNonCommercial-NoDerivs 4.0 International License. The images or other third party material in this article are included in the article's Creative Commons license, unless indicated otherwise in the credit line; if the material is not included under the Creative Commons license, users will need to obtain permission from the license holder to reproduce the material. To view a copy of this license, visit http:// creativecommons.org/licenses/by-nc-nd/4.0/

(c) The Author(s) 2017 